\title{
Incidence and Nature of Negotiations for Meaning during Uncontrolled Speaking Practice in English as a Foreign Language Classrooms
}

\author{
Edgar Emmanuell Garcia-Ponce \\ Universidad de Guanajuato
}

\begin{abstract}
Correspondence concerning this article should be addressed to Edgar Garcia-Ponce, Departamento de Lenguas, Universidad de Guanajuato, Calzada de Guadalupe S/N, Colonia, Centro, C.P: 36000, Guanajuato, Mexico.E-mail: ee.garcia@ugto.mx
\end{abstract}

\author{
Irasema Mora-Pablo
}

Universidad de Guanajuato

\begin{abstract}
Correspondence concerning this article should be addressed to Irasema Mora-Pablo, Departamento de Lenguas, Universidad de Guanajuato, Calzada de Guadalupe S/N, Colonia, Centro, C.P: 36000, Guanajuato, Mexico.E-mail: imora@ugto.mx
\end{abstract}

\begin{abstract}
The past three decades have seen an increasing interest in negotiation for meaning as interactional processes which advance language acquisition. Motivated by this claim, a number of studies have set out to determine the tasks that best promote negotiations for meaning (NfMs). However, this research has mostly tended to investigate NfM under experimental conditions, leaving considerably unexplored the negotiated interactions that might take place in real English as a foreign language (EFL) classrooms. In response to this, the present study sets out to investigate the incidence and nature of NfM in three uncontrolled EFL classrooms. In examining several teacher- and learner-led speaking tasks at basic, intermediate and advanced levels, the findings indicate that the amount of NfM is lower than those reported in previous studies. Moreover, a qualitative analysis of the interactional data suggests that the NfM across proficiency levels was limited in nature, and thus did not provide learners with all the learning benefits inherent in negotiation for meaning. These findings raise intriguing questions as to teachers' and learners' opportunities to negotiate meaning during EFL classroom interactions, and ways through which they can promote negotiated interactions in their EFL classrooms.
\end{abstract}

Keywords: English as a foreign language, negative evidence, negotiation for meaning, speaking practice

For more than three decades, interactionist research has drawn attention to the interactional processes inherent in negotiation for meaning (NfM) because these conversational adjustments are claimed to encourage L2 acquisition (Long, 1996; Pica, 1996). However, this construct has been surrounded by controversy (Garcia-Ponce, Mora-Pablo, Crawford Lewis \& Lengeling, 2017). Firstly, it has been found to be scarce in the language classroom (Foster, 1998; Foster \& Ohta, 2005; García Mayo \& Pica, 2000; to name just a few). Secondly, despite the importance attributed to NfM, its nature and potential effects on language acquisition have been mostly investigated under controlled conditions which do not reflect the interactions that are commonly initiated in real language classrooms (see, for example, Hull \& Saxon, 2009; Yi \& Sun, 2013).

In response to the above, the present study set out to investigate the incidence and nature of NfMs during uncontrolled interactions in three EFL classrooms in a Mexican university, aiming to respond to Foster's (1998) call for studies which investigate NfMs during 
classroom interactions which are not intentionally modified. In contrast to other studies, we focus on NfMs during speaking practice in particular, rather than teaching and learning practices in general, since these interactions (should) provide EFL teachers and learners with opportunities to focus on the development of speaking skills "through meaningful communication by expressing, interpreting, and negotiating meaning" (Burke, 2011, p. 9). This thus allows us to understand - from naturalistic and exploratory perspectives - the incidence and nature of negotiated interactions which arguably take place in the EFL classroom. By doing this, the study aims to enhance our understanding of the extent to which uncontrolled interactions in EFL classrooms are conducive to promoting opportunities for teachers and learners to negotiate meaning and thus foster language acquisition. The study is guided by the following research questions (RQs):

1. How often do EFL teachers and learners engage in negotiation for meaning during uncontrolled teacher- and learner-led speaking tasks?

2. What is the nature of the negotiation for meaning during these EFL interactions?

As implied in the research questions, the present study adopts a naturalistic perspective of the tasks, interactions and the NfMs that were initiated. This involved not only counting frequencies of negotiations and the triggers that initiated them, but also exploring their qualitative characteristics with the help of transcribed data.

This paper begins by reviewing literature concerning negotiation for meaning. After outlining the study, participants, and data collection and analysis, it will then go on to discuss the findings of the interactional data. It concludes by suggesting some implications, and further research areas to consolidate and generalize from these findings.

\section{Negotiation for Meaning During Classroom Interactions}

The construct of NfM is founded on Krashen's (1982) claim that second language acquisition is fostered when learners are exposed to comprehensible input. Long (1996) agrees with Krashen (1982) that the provision of comprehensible input is fundamental, but maintains it is not a sufficient condition for second language acquisition. According to Long (1996), learners benefit from greater language learning opportunities when input is modified interactionally rather than solely being exposed to great amounts of comprehensible input. These opportunities are facilitated during NfM which serves the comprehension, feedback, and production needs of language learners (Long, 1983, 1996). Specifically, during these conversational adjustments, input is made comprehensible by teachers and learners working together towards coconstructing meanings (Walsh, 2013), ensuring that the classroom discourse progresses smoothly by checking, repeating, clarifying, or modifying problem utterances in phonological, morphosyntactic, lexical and syntactic manners (Foster \& Ohta, 2005). Besides increasing input comprehensibility, NfM provides learners with opportunities to receive negative evidence (i.e., language data concerning the correctness of their utterances) (Long, 1996), and modify their output towards greater comprehensibility, complexity and accuracy (Swain, 2000, 2005).

Motivated by the above, a considerable number of studies since the mid-1980s have set out to determine the classroom conditions and tasks that best encourage learners to engage in NfM. In particular, groups of non-native speakers rather than teacher-led discussions, and information gap tasks performed in dyads have been claimed to promote opportunities for NfM (Doughty \& Pica, 1986). Nevertheless, research evidence has shown that NfM tends to be short (Foster, 1998), and performed at word level (Foster \& Ohta, 2005; Shi, 2004), that is, negotiation for vocabulary or expressions rather than content or grammar structures. Furthermore, it has been found that teachers and learners engage in negotiated interactions to increase comprehensibility rather than the accuracy of learners' messages (Pica, 1996). Besides the limited nature of NfM, there is also statistical evidence indicating that the incidence of NfM is scarce during classroom interactions (see Foster, 1998; Foster \& Ohta, 2005; García Mayo \& Pica, 2000; Van der Zwaard \& Bannink, 2016). For example, Foster (1998), motivated by the claim that small group work promotes learner interaction, coded and compared the incidence of NfM in dyads and small groups during tasks involving required and optional information exchanges. She found that the incidence of NfM in both groups was generally low. Surprisingly, in exploring the distribution of $\mathrm{NfM}$ within the groups, she found that some learners dominated the NfM moves, whereas others were not overtly engaged in negotiating meaning. Similarly, Foster and Ohta (2005) explored the frequency of NfM moves in dyads and triads during information exchange tasks. They found that the incidence of NfM was low across their datasets.

Reasons for the scarcity of NfM in the language classroom are still not clear. Long (1996) acknowledges that the opportunities for NfM are often unnoticed by language teachers due to the fast pace of classroom interactions. Foster (1998) explains that holding up the interactions every time there is a message difficulty may be a way of making the interaction or task frustratingly slow. It has also been suggested that teachers and learners may avoid these interactional 
adjustments if they perceive them as face-threatening (Foster, 1998; Naughton, 2006, Van der Zwaard \& Bannink, 2016), or as a sign of incompetence (Foster \& Ohta, 2005). Due to the fact that NfM is "a rare commodity in classrooms" (Pica, 1996, p. 254), these interactional adjustments have been investigated in experimental conditions, e.g., a tighter design of tasks, laboratory settings, and a narrow number of participants who volunteer, etcetera. Due to the fact that previous research has controlled classroom conditions in order to investigate NfM, it is possible to suggest that such findings may not relate to teaching and learning practices which are commonly initiated in real language classrooms. Moreover, the fact that learners in these studies tend to volunteer their time raises questions about the extent to which their interactional behaviour in an experimental setting is the same during uncontrolled classroom interactions (Foster, 1998). In EFL contexts, this becomes a problem for teachers and learners because it is still not clear whether classroom interactions where mostly nonnative teachers and learners interact are environments where comprehensible input and comprehensible output through negotiated interactions are facilitated.

The above highlights the need to explore the quantity and quality of NfM during uncontrolled interactions in order not to disrupt the classrooms and compromise the data (see Foster, 1998). In response to this, the present study attempts to investigate to what extent NfM is promoted when EFL teachers and learners and learner peers engage in interactions to practise speaking during normal classroom conditions. The decision not to control classroom conditions responds to Jakobovits and Gordon's (1974) suggestion that research should not be conducted in controlled conditions if the purpose is to understand and enhance teaching and learning practices. This decision, in turn, enables an understanding of the opportunities that EFL teachers and learners in this context have to negotiate meaning and thus benefit from input that is made comprehensible interactionally during classroom interactions which reflect their common teaching and learning practices. In order to attain this, we examine the incidence and nature of communication breakdowns that lead to NfM by identifying and quantifying NfM moves in three classrooms at basic, intermediate and advanced levels.

\section{Materials and Methods}

\section{Research Context}

The present study was carried out in a state university in Mexico. Learners in this teaching and learning context are expected to learn English to a proficiency level that enables them to work as EFL teachers upon completing a five-year teacher training programme. Specifically, the study was conducted in three English classes: basic, intermediate, and advanced levels. Classes at basic and intermediate levels involve six hours of English study per week, where three hours are centred on learning vocabulary and grammar and the other three on practising the language. In English classes at advanced levels, learners study vocabulary and grammar for two hours per week, and practise the language for three hours per week.

\section{Participants}

All the learners enrolled in the three English classes participated (17 at the basic level; 26 at the intermediate level; and 20 at the advanced level). A small survey conducted to identify their backgrounds indicated the following: 1) they were all Mexicans; 2) their ages ranged from 18 to 24 years; 3 ) they all spoke Spanish as an L1. Their educational backgrounds were mainly from state schools, where exposure to the second language is normally five hours per week in classrooms of approximately 30-40 learners. A small number of learners had educational backgrounds from private schools, where exposure to English ranges from 15 to 20 hours per week. Three female teachers participated in the study, all of whom were originally from Mexico and shared Spanish as a mother tongue. They all stated that they had been learning English for 14 or more years, and teaching it for seven or more years.

\section{Procedures}

According to Larsen-Freeman and Long (1991), recorded classroom interactions can provide a detailed and comprehensive description of participants' interactional behaviour and patterns in an unrestricted way because of the naturally occurring nature of the data. Following this claim, classroom interactions were recorded during speaking practice because, as previously discussed, these interactions (should) provide opportunities for teachers and learners to express, interpret, and negotiate meaning (Burke, 2011). The teachers and learners knew that they were being recorded, but after several minutes they seemed to forget about the presence of the recorders and carried on with the speaking practice. One researcher was present during the recorded classroom interactions in order to take notes about the teaching and learning practices, but he maintained an onlooker role in order not to disturb and influence the classroom interactions. 
In line with the exploratory and naturalistic approach adopted in the study, the teachers' individual teaching style, speaking tasks, structure of the classes, number of learners, and class time were neither modified nor controlled during the recorded classroom interactions. As summarised in Table 1, speaking practice at the three proficiency levels was led by the teachers, i.e., teacher-led interactions (TLIs) defined as discussions led by teachers which serve the purpose of practicing speaking, and by the learners, i.e., learner-led interactions (LLIs) described as interactional discourse constructed by learners in pairs or, in a few instances, in trios to practise speaking. We were particularly interested in exploring NfMs the LLIs because they are believed to provide a non-threatening atmosphere and encourage negotiated interactions among learner peers (Foster, 1998). Moreover, the TLIs and LLIs comprised speaking tasks that focused on meaning and accuracy, as described below.

Table 1

Focus of speaking tasks at the three proficiency levels

\begin{tabular}{llll}
\hline & Basic & Intermediate & Advanced \\
\hline \multirow{2}{*}{ Meaning } & 2 TLIs & 3 TLIs & 0 TLIs \\
& 3 LLIs & 6 LLIs & 6 LLIs \\
\hline \multirow{2}{*}{ Accuracy } & 3 TLIs & 1 TLI & 2 TLIs \\
& 3 LLIs & 0 LLIs & 0 LLIs \\
\hline
\end{tabular}

TLIs and LLIs requiring learners to use language communicatively, with an emphasis on meaning and to attain a real-world objective, were classified as following a focus on meaning, whereas TLIs and LLIs during which learners practised specific grammar structures or vocabulary were classified as following a focus on accuracy. In total, 600 minutes of classroom interactions were recorded, 200 minutes approximately from each proficiency level.

All participants were informed about how the data were going to be treated in this study, and of their right not to participate or to withdraw at any time. They all stated their willingness to participate, and provided signed consent forms. In order to protect their privacy, the learners' names and identities were carefully rendered anonymous in the data. Instead of real names, abbreviations and pseudonyms are used. The words 'Teacher' (or letter ' $\mathrm{T}$ ') and 'Learner' (or letter 'L' and an identification number, e.g., Learner 5) are used to refer to these teachers and learners in the extracts, analysis and discussions.

\section{Measures}

The analysis of the incidence and nature of NfMs in the TLIs and LLIs at the three proficiency levels followed the idea in cognitive research that the more often learners negotiate meaning, the better for their language development (Foster, 1998). This firstly involved examining the communication breakdowns that lead to NfM through the identification and quantification of NfM moves, which are outlined in the two tables below. Secondly, NfMs were explored from a qualitative perspective with a view to understanding their nature during classroom interactions at the three proficiency levels.

Table 2

Negotiation moves

\begin{tabular}{ll}
\hline Check Moves & Specification \\
\hline 1.Comprehension checks & $\begin{array}{l}\text { These are any expressions, mostly } \\
\text { in the form of questions, initiated } \\
\text { to establish whether a preceding } \\
\text { utterance has been understood } \\
\text { by the interlocutor (Long, 1980). }\end{array}$
\end{tabular}

2.Confirmation checks

These are initiated to elicit confirmation that a preceding utterance by the interlocutor has been correctly understood or heard by the speaker (Long, 1980).

3.Clarification requests

These are mostly wh- or bipolar questions initiated to elicit clarification of the interlocutor's preceding utterance(s). These questions require the interlocutor to either furnish new information or recode information previously given (Long, 1980).

According to Long (1996), NfMs are also a source of negative evidence, i.e., explicit or implicit information that is provided to learners concerning (grammatical) errors in their oral production (Gass, 2003). Negative evidence during NfMs can take several forms, including grammar explanations, explicit feedback, recasts, and communication breakdowns followed by repair sequences (Long, 1996). In order to explore learners' opportunities to receive and provide negative evidence during NfM, we also coded and explored corrective repetitions (explicit feedback) and recasts (explicit feedback), as detailed in Table 3.

Because the purpose of the study was not to test hypotheses, but to explore the incidence and nature of NfM in EFL classrooms, the data were calculated using simple total, ratios and averages. Firstly, the total numbers were obtained by counting the occurrences of NfMs and the moves that triggered them. Secondly, ratios between NfMs per minute were calculated by dividing the total number of NfMs in each TLI or PLI per the total number of minutes of each interaction. 
Table 3

Negative evidence moves

\begin{tabular}{|c|c|}
\hline Move & Specification \\
\hline 4.Corrective repetitions & $\begin{array}{l}\text { These serve the purpose of reshaping } \\
\text { another speaker's utterance. These are } \\
\text { the most common types of feedback } \\
\text { to provide negative evidence which } \\
\text { usually contain an additional feature, } \\
\text { for example, stress or lengthening of a } \\
\text { segment, questioning intonation, etc. } \\
\text { (Chaudron, 1988). }\end{array}$ \\
\hline
\end{tabular}

5.Recasts

These are ways in which participants reshape, reformulate or refine all or part of others' utterances (Long, 1996; Walsh, 2006). The criteria to consider a recast are: 1) they contain content words of a preceding incorrect utterance; 2) they reshape utterances in a phonological, syntactic, morphological or lexical way; and 3) they focus on meaning rather than on form (Long \& Robinson, 1998).

\section{Results and Discussion}

\section{Incidence of Negotiation for Meaning}

In addressing RQ1 (i.e., how often do EFL teachers and learners engage in negotiation for meaning during uncontrolled teacher- and learner-led speaking tasks?), the findings in this section show that the incidence of NfMs was varied but generally low during the TLIs and LLIs at the three proficiency levels, and mostly initiated by confirmation checks and clarification requests. The findings into the scarcity of NfMs during the TLIs and LLIs were not expected because there is research evidence which suggests that NfM tends to occur in NNS interactions (Varonis \& Gass, 1985), twoway exchange tasks (Foster, 1998), more frequently in peer- than in teacher-led discussions (Ellis, 2012), and in dyads rather than small groups (Foster, 1998).

Table 4 shows that the basic teacher and learners engaged in two to eight NfMs during the TLIs, with a range of 0.7 to $2.2 \mathrm{NfMs}$ per minute. As shown in this table, meaning was negotiated through checking confirmations and requesting clarifications. NfMs involving corrective repetitions tended to be frequent in these interactions, but recasts were the scarcest. It is possible that the basic teacher was compelled to provide negative feedback and correct the learners' turns by repeating their contributions due to the learners' beginner proficiency level. However, as we shall see, these NfM moves were absent in the TLIs and LLIs at the intermediate and advanced levels. Across these TLIs, comprehension checks did not trigger any
Table 4

Negotiation for meaning in the TLIs (basic level)

\begin{tabular}{|c|c|c|c|c|c|c|}
\hline & $\begin{array}{c}\text { TLI } \\
1 \\
\end{array}$ & $\begin{array}{c}\text { TLI } \\
2 \\
\end{array}$ & $\begin{array}{c}\text { TLI } \\
3 \\
\end{array}$ & $\begin{array}{c}\text { TLI } \\
4 \\
\end{array}$ & $\begin{array}{c}\text { TLI } \\
5\end{array}$ & Average \\
\hline Time of activity & $1: 24$ & $5: 20$ & $7: 20$ & $5: 13$ & $2: 45$ & \\
\hline No. of NfMs & 3 & 3 & 8 & 5 & 2 & 4.2 \\
\hline NfMs per minute & 2.2 & 0.5 & 1.0 & 0.9 & 0.7 & 1.0 \\
\hline $\begin{array}{l}\text { Comprehension } \\
\text { check }\end{array}$ & 0 & 1 & 1 & 2 & 0 & 0.8 \\
\hline $\begin{array}{l}\text { Confirmation } \\
\text { check }\end{array}$ & 2 & 1 & 6 & 1 & 1 & 2.2 \\
\hline $\begin{array}{l}\text { Clarification } \\
\text { request }\end{array}$ & 2 & 1 & 1 & 4 & 1 & 1.8 \\
\hline $\begin{array}{l}\text { Corrective } \\
\text { repetition }\end{array}$ & 0 & 2 & 0 & 2 & 1 & 1.0 \\
\hline Recast & 0 & 0 & 1 & 0 & 1 & 0.4 \\
\hline $\begin{array}{l}\text { No. of NfM } \\
\text { moves }\end{array}$ & 4 & 5 & 9 & 9 & 4 & 6.2 \\
\hline
\end{tabular}

$\mathrm{NfM}$ due to their function as discourse markers rather than to initiate NfMs. In the next section, we provide interactional evidence that illustrates how the three teachers' comprehension checks typically served a purpose as discourse markers, not triggering NfMs across the datasets.

In the case of the LLIs, Table 5 shows an increase of NfMs compared to the NfMs in the TLIs (an average of 1.5 NfMs per LLI compared to $1.0 \mathrm{NfMs}$ per TLI).

Table 5

Negotiation for meaning in the LLIs (basic level)

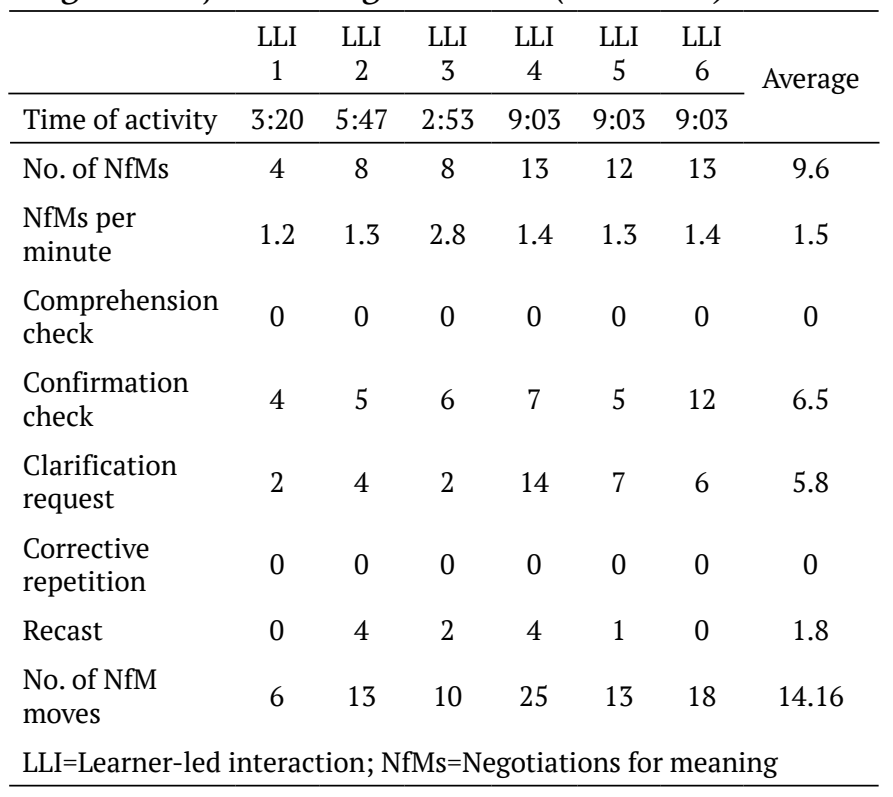

Learners engaged in four to $13 \mathrm{NfMs}$ across the LLIs, ranging from 1.2 to 2.8 NfMs per minute. As in the TLIs, the NfMs were mostly initiated to check confirmations and request clarifications. Interestingly, 
the learners engaged in a higher number of NfMs involving recasts in the LLIs than in the TLIs, during which the teachers may have avoided them in order to maintain the learners' face. In these LLIs, NfMs triggered by comprehension checks and corrective repetitions were absent.

Unlike at the basic level, Tables 6 and 7 show that the TLIs at the intermediate level promoted a greater number of NfMs than the LLIs (an average of $1.1 \mathrm{NfMs}$ per minute in the TLIs compared to $0.5 \mathrm{NfMs}$ per minute in the LLIs), and more than the TLIs at the basic and advanced level (see Tables 4 and 8, respectively). However, as in other interactions at the other two proficiency levels, NfMs were mostly initiated by confirmation checks and clarification requests.

Table 6

Negotiation for meaning in the TLIs (intermediate level)

\begin{tabular}{|c|c|c|c|c|c|}
\hline & $\begin{array}{c}\text { TLI } \\
1 \\
\end{array}$ & $\begin{array}{c}\text { TLI } \\
2 \\
\end{array}$ & $\begin{array}{c}\text { TLI } \\
3 \\
\end{array}$ & $\begin{array}{c}\text { TLI } \\
4 \\
\end{array}$ & Average \\
\hline Time of activity & $6: 16$ & $7: 20$ & $12: 55$ & $5: 21$ & \\
\hline No. of NfMs & 9 & 10 & 13 & 4 & 9.0 \\
\hline NfMs per minute & 1.4 & 1.3 & 1.0 & 0.7 & 1.1 \\
\hline $\begin{array}{l}\text { Comprehension } \\
\text { check }\end{array}$ & 0 & 0 & 3 & 4 & 1.7 \\
\hline $\begin{array}{l}\text { Confirmation } \\
\text { check }\end{array}$ & 8 & 7 & 10 & 1 & 6.5 \\
\hline $\begin{array}{l}\text { Clarification } \\
\text { request }\end{array}$ & 4 & 5 & 6 & 4 & 4.7 \\
\hline $\begin{array}{l}\text { Corrective } \\
\text { repetition }\end{array}$ & 0 & 0 & 0 & 0 & 0 \\
\hline Recast & 0 & 1 & 2 & 0 & 0.7 \\
\hline No. of NfM moves & 12 & 13 & 21 & 9 & 13.7 \\
\hline
\end{tabular}

Table 6 shows that the teacher and learners during the TLIs engaged in a range of four to $13 \mathrm{NfMs}, 1.0$ to $1.4 \mathrm{NfMs}$ per minute. Again, most of these NfMs involved a greater number of confirmation checks and clarification requests than comprehension checks. NfMs to provide negative evidence were not frequent in these TLIs.

Table 7 shows that the learners in the LLIs engaged in three to seven NfMs, 0.3 to $0.8 \mathrm{NfMs}$ per minute, mostly initiated by confirmation checks and clarification requests. As in the basic LLIs, there is a slight increase of NfMs triggered by recasts in the LLIs compared to the TLIs (an average of 0.8 recasts per LLI compared to 0.7 recasts per TLI). Moreover, comprehension checks and corrective repetitions were absent in these LLIs.

At the advanced level, Table 8 shows that the teacher and learners in the TLIs engaged in only one NfM.

This NfM, initiated in TLI 1, involved one confirmation check. As pointed out previously, the seven comprehension checks did not initiate any NfMs due to their function as discourse markers. However, the NfMs increased in the LLIs, as shown below.

Table 7

Negotiation for meaning in the LLIs (intermediate level)

\begin{tabular}{|c|c|c|c|c|c|c|c|}
\hline & $\begin{array}{c}\text { LLI } \\
1 \\
\end{array}$ & $\begin{array}{c}\text { LLI } \\
2\end{array}$ & $\begin{array}{c}\text { LLI } \\
3\end{array}$ & $\begin{array}{c}\text { LLI } \\
4 \\
\end{array}$ & $\begin{array}{c}\text { LLI } \\
5\end{array}$ & $\begin{array}{c}\text { LLI } \\
6 \\
\end{array}$ & \\
\hline $\begin{array}{l}\text { Time of } \\
\text { activity }\end{array}$ & $8: 31$ & $8: 31$ & $8: 31$ & 13:02 & 13:02 & 13:02 & Average \\
\hline No. of NfMs & 7 & 6 & 3 & 7 & 7 & 7 & 6.1 \\
\hline $\begin{array}{l}\text { NfMs per } \\
\text { minute }\end{array}$ & 0.8 & 0.7 & 0.3 & 0.5 & 0.5 & 0.5 & 0.5 \\
\hline $\begin{array}{l}\text { Comprehension } \\
\text { check }\end{array}$ & 0 & 0 & 0 & 0 & 0 & 0 & 0 \\
\hline $\begin{array}{l}\text { Confirmation } \\
\text { check }\end{array}$ & 3 & 5 & 3 & 7 & 5 & 4 & 4.5 \\
\hline $\begin{array}{l}\text { Clarification } \\
\text { request }\end{array}$ & 2 & 1 & 0 & 1 & 2 & 5 & 1.8 \\
\hline $\begin{array}{l}\text { Corrective } \\
\text { repetition }\end{array}$ & 0 & 0 & 0 & 0 & 0 & 0 & 0 \\
\hline Recast & 4 & 0 & 0 & 0 & 1 & 0 & 0.8 \\
\hline $\begin{array}{l}\text { No. of NfM } \\
\text { moves }\end{array}$ & 9 & 6 & 3 & 8 & 8 & 9 & 7.1 \\
\hline
\end{tabular}

Table 8

Negotiation for meaning in the TLIs (advanced level)

\begin{tabular}{lccc}
\hline & TLI 1 & TLI 2 & \multirow{2}{*}{ Average } \\
\cline { 1 - 3 } Time of activity & $1: 50$ & $5: 40$ & \\
\cline { 1 - 3 } No. of NfMs & 1 & 0 & 0.5 \\
NfMs per minute & 0.5 & 0 & 0.2 \\
Comprehension check & 0 & 7 & 3.5 \\
Confirmation check & 1 & 0 & 0.5 \\
Clarification request & 0 & 0 & 0 \\
Corrective repetition & 0 & 0 & 0 \\
Recast & 0 & 0 & 0 \\
No. of NfM moves & 1 & 7 & 4 \\
\hline
\end{tabular}

TLI=Teacher-led interaction; NfMs=Negotiations for meaning

Table 9 shows that the advanced learners engaged in three to seven NfMs, 0.2 to $0.7 \mathrm{NfMs}$ per minute. As at the basic and intermediate levels, these NfMs mostly involved confirmation checks, clarification requests and recasts. In comparing the LLIs at the three proficiency levels, it is evident that the advanced learners engaged in the lowest number of NfMs. The immediate issue that emerges from this finding is that the advanced learners in both TLIs and LLIs had the most limited opportunities to negotiate input, and receive and provide negative evidence across proficiency levels. 
Table 9

Negotiation for meaning in the LLIs (advanced level)

\begin{tabular}{|c|c|c|c|c|c|c|c|}
\hline & $\begin{array}{l}\text { LLI } \\
1\end{array}$ & $\begin{array}{l}\text { LLI } \\
2\end{array}$ & $\begin{array}{l}\text { LLI } \\
3\end{array}$ & $\begin{array}{c}\text { LLI } \\
4\end{array}$ & $\begin{array}{l}\text { LLI } \\
5\end{array}$ & $\begin{array}{c}\text { LLI } \\
6\end{array}$ & \multirow{2}{*}{ Average } \\
\hline $\begin{array}{l}\text { Time of } \\
\text { activity }\end{array}$ & $11: 42$ & $11: 42$ & $11: 42$ & $6: 20$ & $6: 20$ & $6: 16$ & \\
\hline No. of NfMs & 5 & 7 & 3 & 4 & 5 & 4 & 4.6 \\
\hline $\begin{array}{l}\text { NfMs per } \\
\text { minute }\end{array}$ & 0.4 & 0.5 & 0.2 & 0.6 & 0.7 & 0.6 & 0.5 \\
\hline $\begin{array}{l}\text { Comprehension } \\
\text { check }\end{array}$ & 0 & 0 & 0 & 0 & 0 & 0 & 0 \\
\hline $\begin{array}{l}\text { Confirmation } \\
\text { check }\end{array}$ & 3 & 2 & 2 & 2 & 5 & 5 & 3.1 \\
\hline $\begin{array}{l}\text { Clarification } \\
\text { request }\end{array}$ & 2 & 3 & 0 & 2 & 1 & 3 & 1.8 \\
\hline $\begin{array}{l}\text { Corrective } \\
\text { repetition }\end{array}$ & 0 & 0 & 0 & 0 & 0 & 0 & 0 \\
\hline Recast & 0 & 3 & 1 & 0 & 0 & 0 & 0.6 \\
\hline $\begin{array}{l}\text { No. of NfM } \\
\text { moves }\end{array}$ & 5 & 8 & 3 & 4 & 6 & 0 & 4.3 \\
\hline
\end{tabular}

LLI=Learner-led interaction; NfMs=Negotiations for meaning

As indicated by the above interactional data, the learners during the TLIs and PLIs at the three proficiency levels engaged in NfMs which ranged from zero to 13 , from 0 to $2.8 \mathrm{NfMs}$ per minute. These figures indicate that the incidence of NfMs was significantly varied and generally low at the three proficiency levels, as consistent with previous research (Foster, 1998; García Mayo \& Pica, 2000; Walsh, 2002; to name just a few). Zero to $13 \mathrm{NfMs}$ in this study are found to be lower than in other empirical studies (see, for example, Foster, 1998; Foster \& Ohta, 2005). Despite claims that classroom communication should be conducive to promoting negotiated interactions (Long, 1996), these figures suggest that uncontrolled classroom interactions during speaking practice may not promote opportunities for teachers and learners to negotiate meaning and thus benefit from its inherent learning conditions. The findings into the low incidence of NfMs during the LLIs are somewhat surprising since learners are thought to engage in a higher number of NfMs in peer- than in teacher-led discussions (Ellis, 2012; Pica, 1996). Moreover, despite claims that NfMs tend to occur in tasks requiring a two-way exchange of information (Foster, 1998), the intermediate and advanced LLIs, which met this requirement, did not appear to promote NfMs. As we will see in the remainder of this paper, the interactional data show that the NfMs across proficiency levels were limited not only in number but also in nature.

\section{Nature of Negotiation for Meaning}

In addressing RQ2 (i.e., what is the nature of the negotiation for meaning during these EFL interactions?), the interactional data show that the NfMs were typically performed around lexical forms rather than syntactic structures or learners' wider meaning or intention. In other words, the teachers and learners across proficiency levels engaged in interactional adjustments to negotiate meaning of single words or expressions in response to misunderstandings or mispronunciations. The following two extracts illustrate how the teachers and learners in the TLIs and learner peers in the LLIs typically engaged in NfMs at word level:

\section{Extract 1}

A negotiation for meaning in TLI 2 (basic level)

13. T: //so let's move on to exercise $2 / / . . . / /$ what are the instructions L6?//

14. L6: ((4)) [inaudible]

15. T: //Speak up L6// ... //again but speak up//

16. L6://Listen egain// $\rightarrow$

17. T://LisTEN!//

18. L6: //Listen egain// $\rightarrow$

19. T://Again!//

20. L6: //Again// ...//complete the sentence with words ... from the box/l

21. T: //Ok//...//let's look at the words ... from the box $/ /$...// you have ... 'a man' 'by bus'// ... what else?//

$\mathrm{T}=$ Teacher; $\mathrm{L} \#=$ Learner and its number in the interaction; $/ /=$ AS-unit boundary; <>=clause boundary

In Extract 1, an NfM is triggered in turns 16 and 18 by L6's mispronunciation of the words /listen again/. In turns 17 and 19, the teacher corrects the learner's mispronunciation by repeating her words. The NfM finishes with L6's uptake in turn 20 and the teacher's signal of acceptance in turn 21. In Extract 2 (below), L4 triggers an NfM in turn 227 as a result of her lack of knowledge of the Spanish word /saco/ in English. In turns 228 and 229, L13 and L2 provide L4 with the unknown word. The NfM ends with L4 repeating and taking up the word.

\section{Extract 2}

A negotiation for meaning in a LLI (intermediate level)

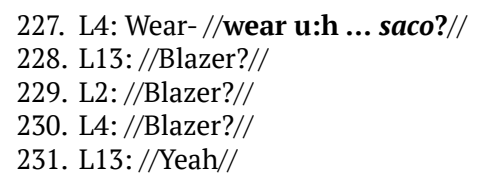

$\mathrm{L} \#=$ Learner and its number in the interaction;

$/ /=$ AS-unit boundary; <>=clause boundary

As shown in the above extracts, the teacher and learners engaged in NfMs which involved adjustments of mispronunciations, or a lack of knowledge, regarding individual words or expressions. The nature of these NfMs at word level support previous empirical studies 
(Foster, 1998; Foster \& Ohta, 2005; Sheen, 2004; Shi, 2004), which also found that NfMs tended to be short and answered briefly, and normally performed for adjusting lexical items rather than larger stretches of discourse or grammatical morphology. However, as discussed below, the present study goes further to suggest that the limited quantity and quality of NfM may be in response to the teachers' and learners' perceptions and beliefs.

Moreover, the interactional data indicated that NfMs were mostly triggered by confirmation checks and clarification requests, as illustrated in the interactional data in Extract 3.

\section{Extract 3}

A negotiation for meaning in TLI 1 (basic level)

38. T: [...] okay what other things you take with you?

39. L16: //Take a brik// [sic]

40. T: Take a?

41. $\mathrm{L} 16: / / \mathrm{Brik} / /[$ sic $]$

42. T: Brik? [sic]

43. L16://Break//

$\mathrm{T}=$ Teacher; $\mathrm{L} \#=$ Learner and its number in the interaction; //=AS-unit boundary; <>=clause boundary

As shown in Extract 3, the teacher and L16 engage in an NfM initiated by the mispronunciation of the word /break/. In order to correct L16, the teacher initiates two confirmation checks that assist L16 in focusing her attention on the mispronunciation, which is corrected by L16 in Line 43. The recurrence of NfMs triggered by confirmation checks and clarification requests may be explained by the teachers' and learners' possible perceptions and beliefs about them as more effective interactional strategies to provide or elicit target-like language forms without involving a loss of learners' face. This suggestion is supported by the interactional evidence itself which showed that NfMs initiated by corrective repetitions were scarce across the datasets, and NfMs triggered by recasts were more frequent in the LLIs than in the TLIs. From a social perspective, NfMs to provide negative evidence during the TLIs may have been perceived by the teachers and learners as face-threatening, motivating them to avoid engaging in them in order not to involve a loss of face. This suggestion is supported by Foster (1998), Foster and Ohta (2005) and Naughton (2006), who suggest that NfMs which involve a potential loss of face and/or discouraging detours may be avoided by teachers and learners. In contrast, the LLIs at the three proficiency levels appeared to encourage the learners to engage in NfMs to provide each other with negative evidence, at least implicitly. The following extract illustrates how the learners in the LLI typically engaged in NfMs involving recasts:

\section{Extract 5}

A recast in PLI 1 (intermediate level)

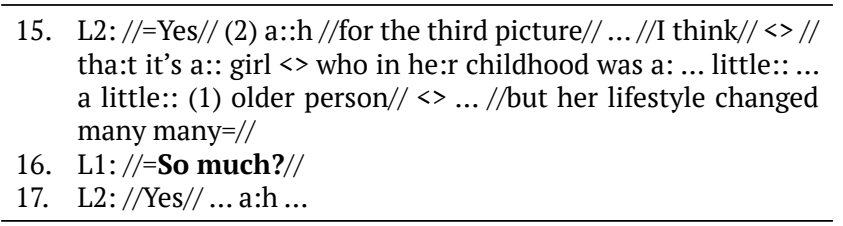

$\mathrm{L} \#=$ Learner and its number in the interaction; //=AS-unit boundary; <>=clause boundary

In Extract 5, L2 describes a picture in turn 15 and incorrectly say /her lifestyle changed many many/, whose last part L1 restructures in turn 16. The NfM finishes with L2 signalling comprehension in turn 17. As illustrated in Extract 5, the learners during the LLIs were able to reformulate each other's utterances into more target-like forms. This implies that the LLIs, a more intimate and less face-threatening environment than TLIs (see McDonough, 2004), may have encouraged learners to engage in NfMs to provide and receive negative evidence. This suggestion is supported by previous empirical studies (Figueiredo, 2006; Foster \& Ohta, 2005; García Mayo \& Pica, 2000), in which NfMs to perform recasts or provide negative evidence were found to be recurrent in peer-led discussions, enabling learners to push their utterances towards target-like structures. However, this evidence in turn highlights the limitations of TLIs to promote NfMs during which negative evidence is facilitated to the learners. Comprehension checks were only initiated by the teachers during the TLIs. However, they did not trigger any NfM since they appeared to be used as discourse markers rather than NfM moves.

The following extract illustrates how the teachers typically used these moves during classroom interactions across the data:

\section{Extract 4}

Comprehension checks in TLI 2 (advanced level)

28. T: [..]//what's the difference between 'siesta' and 'snooze'?//

29. L5: //The first factor ... it's intentionally//

30. $\mathrm{T}$ ://It is intentional// and //it is usually a habit [1]// okay? [1] //well you have a siesta after lunch L4?//

31. L4://Yes//

32. T: //And 'snooze' is probably one day// <>//that you feel tired// ... //you snooze ... okay? Well 'snore'?// [2] //it's to make these sounds// heheh okay?//

33. L5: Ah!

$\mathrm{T}=$ Teacher; $\mathrm{L} \#=$ Learner and its number in the interaction; //=ASunit boundary; <>=clause boundary

In Extract 4, the teacher and learners (advanced level) define and explain some verbs related to sleeping habits. As shown in turns 30 and 32 , the teacher explains the meaning of /siesta/ and /snooze/. In these turns, the teacher contributes with several 'okay?' expressions which appear to check the learners' comprehension. However, none of these checks 
triggered NfMs. Instead, it seems that they served the purpose of organizing and managing what the teachers were saying. That is, comprehension checks, like the above, functioned as discourse markers rather than moves that triggered NfMs.

As discussed above, the interactional data indicated that NfMs across proficiency levels had the following characteristics: (1) were scarce in number; (2) were performed for negotiating lexical forms rather than syntactic structures or general meaning; (3) were mostly initiated by confirmation checks and clarification requests; (4) were limited in negative evidence in the TLIs. This interactional evidence suggests that in general the uncontrolled TLIs and LLIs in which the teachers and learners engaged to practice speaking did not entirely facilitate learners with opportunities to do the following: firstly, negotiate meaning; secondly, provide and receive negative evidence; thirdly, modify their output towards greater accuracy and potential L2 learning. These findings highlight the interactional limitations of the EFL classrooms, which are believed to be learners' sole opportunity to practice and develop linguistic as well as interactional skills (Dinçer \& Yeşilyurt, 2013; Philp \& Tognini, 2009; Yoshida, 2013).

This interactional evidence raises intriguing questions as to the factors that are hindering the EFL teachers and learners from engaging in negotiated interactions and thus fully benefitting from their learning conditions. Based on the findings of this study that NfMs to provide negative evidence were limited during classroom interactions, the study suggests that EFL teachers' and learners' opportunities for negotiated interactions may be limited by their own perceptions and beliefs concerning NfMs as interactional processes which might potentially involve a loss of face. If this is the case, then our investigation signals how perceptual factors can limit the incidence and nature of NfM. Thus, further explorations of the interplay between negotiated interactions and teachers' and learners' perceptions and beliefs would be useful to help design action plans through which NfM can then be promoted in the EFL classroom.

\section{Conclusions and Implications}

The primary aim of this study was to explore the incidence and nature of NfMs during uncontrolled interactions in which the teachers and learners practiced speaking in EFL classrooms. The study was motivated by the claims that NfMs are essential for language acquisition (Long, 1996, Pica 1996), yet scarce during classroom interactions (Foster, 1998). The explorations of the NfMs resided in a naturalistic as well as explanatory inquiry. This involved examining NfMs in three on-going English courses without modifying classroom conditions, such as interactions, number of participants, structure and time of lessons, speaking tasks, and teachers' and learners' interactional behaviour.

In response to Foster's (1998) call for studies which investigate NfMs during normal classroom conditions, the findings of this study indicated that the NfMs were varied but generally low in the TLIs and LLIs across proficiency levels. These findings are contrary to previous studies which have suggested that NfMs tend to occur more frequently in NNS interactions (Varonis \& Gass, 1985), predominantly in learnerrather than teacher-led interactions (Doughty \& Pica, 1986), and in dyads rather than small groups (Palma, 2014). In exploring the nature of the NfMs from a qualitative perspective, the data revealed, first, that the meaning of individual words or expressions were mostly negotiated by the teachers and learners and learner peers. Second, NfMs were mostly triggered by confirmation checks and clarification requests. Third, NfMs to provide negative evidence were scarce in the TLIs and LLIs, but more frequent in the LLIs than the TLIs. Based on the evidence that input tended to be modified through confirmation checks and clarification requests, and the higher scarcity of negative evidence in the TLIs than in the LLIs, we put forward the possibility that the NfMs can be perceived by teachers and learners to involve a potential loss of face. This in turn suggests that teachers' and learners' perceptions and beliefs concerning these interactional adjustments are playing a significant role during their classroom interactions. If we want classroom interactions and tasks that encourage opportunities to negotiate meaning where comprehensible input, comprehensible output and negative evidence are available, it is first necessary that teachers and learners are assisted in becoming aware of the effects of their perceptions and beliefs, and can then align these cognitive factors with practices that are more beneficial for negotiating meaning and thus developing the target language.

Taken together, these findings highlight the need to conduct more research into NfM in order to consolidate and generalize from these findings. Firstly, it would be interesting to explore EFL teachers' and learners' perceptions and beliefs in order to understand their impact, if any, on negotiated interactions. In so doing, we would be in a better position to understand ways through which they can be assisted in promoting NfM during normal interactions in EFL classrooms. Secondly, due to the fact that the interactional data were collected in two sessions over two weeks, further research needs to explore NfMs over a longer period with a view to better understanding the incidence 
and nature of NfMs in EFL communication. However, it is hoped that this small-scale study paves the way for future research into NfM in EFL classrooms whose teaching and learning practices were not deliberately modified.

\section{References}

Burke, B. M. (2011). Rituals and beliefs ingrained in world language pedagogy: Defining deep structure and conventional wisdom. Journal of Language Teaching and Research, 2(1), 1-12. DOI:10.4304/ jltr.2.1.1-12

Chaudron, C. (1988). Second language classrooms. New York, NY: Cambridge University Press.

Dinçer, A., \& Yeşilyurt, S. (2013). Pre-service English teachers' beliefs on speaking skill based on motivational orientations. English Language Teaching, 6(7), 88-95. DOI: http://dx.doi. org/10.5539/elt.v6n7p88

Doughty, C., \& Pica, T. (1986). "Information gap" tasks, do they facilitate second language acquisition? TESOL Quarterly, 20(2), 305-25. DOI: $10.2307 / 3586546$

Ellis, R. (2012). Language teaching research and language pedagogy. Malden, MA: Wiley-Blackwell.

Figueiredo, F. J. Q. (2006). A aprendizagem colaborativa: Foco no processo de correção dialogada [Collaborative learning: A focus on the process of correction]. In V. Leffa (Ed.), $A$ interação na aprendizagem de línguas (2nd ed.) (pp. 133-164). Pelotas, Brazil: EDUCAT.

Foster, P., \& Ohta, A. (2005). Negotiation for meaning and peer assistance in second language classrooms. Applied Linguistics, 26(3), 402-430. DOI: 10.1093/ applin/ami014

Foster, P. (1998). A classroom perspective on negotiation for meaning. Applied Linguistics, 19(1), 1-23. DOI: 10.1093/applin/19.1.1

García Mayo, M. P., \& Pica, T. (2000). L2 learner interaction in a foreign language setting: Are learning needs addressed? International Review of Applied Linguistics, 38(1), 35-58. doi: https://doi. org/10.1515/iral.2000.38.1.35

Garcia-Ponce, E. E., Mora-Pablo, I., Crawford Lewis, T., \& Lengeling, M. M. (2017). Effects of teachers' and learners' beliefs on negotiation for meaning and negative feedback during interactions in EFL classrooms. International Journal of Modern Language Teaching and Learning, 2(2), 5466. Retrieved from: http://ijmltl.com/fulltext/ paper-12062017112137.pdf

Gass, S. M. (2003). Input and interaction. In C. Doughty \& M. Long (Eds.), Handbook of second language acquisition (pp. 224-255). Oxford, UK: Blackwell Publishers.

Hull, D., \& Saxon, T. F. (2009). Negotiation for meaning and co-construction of knowledge: An experimental analysis of asynchronous online instruction. Comput. Educ. 52(3), 624-639. http:// dx.doi.org/10.1016/j.compedu.2008.11.005

Jakobovits, L. A., \& Gordon, B. (1974). The context of foreign language teaching. Rowley, Massachusetts: Newbury House.

Krashen, S. (1982). Principles and practice in second language acquisition. Oxford, UK: Pergamon.

Larsen-Freeman, D., \& Long, M. H. (1991). An introduction to second language acquisition research. London, UK: Pearson.

Long, M. H., \& Robinson, P. (1998). Focus on form: Theory, research and practice. In C. Doughty \& J. Williams (Eds.), Focus on form in second language acquisition (pp. 15-41). Cambridge, UK: Cambridge University Press.

Long, M. H. (1980). Input, interaction, and second language acquisition (Unpublished doctoral dissertation). UCLA, Department of Applied Linguistics and TESL, Los Angeles, California.

Long, M. H. (1996). The role of the linguistic environment in second language acquisition. In W. Ritchie \& T. Bhatia (Eds.), Handbook of Second Language Acquisition (pp. 413-468). San Diego, CA: Academic Press.

McDonough, K. (2004). Learner-learner interaction during pair and small group activities in a Thai EFL context. System, 32(2), 207-224. http://dx.doi. org/10.1016/j.system.2004.01.003

Naughton, D. (2006). Cooperative strategy training and oral interaction: Enhancing small group communication in the language classroom. The Modern Language Journal, 90(2), 169-184. DOI: $10.1111 / \mathrm{j} .1540-4781.2006 .00391 . x$

Palma, G. (2014). A classroom view of negotiation of meaning with EFL adult Mexican pupils. Sage Open, 4(2), 1-14. DOI: $10.1177 / 2158244014535941$

Philp, J., \& Tognini, R. (2009). Language acquisition in foreign language contexts and the differential benefits of interaction. International Review of Applied Linguistics, 47(3/4), 245-266. DOI: 10.1515/ iral.2009.011

Pica, T. (1996). The essential role of negotiation in the second language classroom. JALT Journal, 18(2), 241-268. Retrieved from http://jalt-publications. org/files/pdf/jalt_journal/jj-18.2.pdf\#page $=67$

Shi, G. (2004). Teacher's corrective feedback and learner repair in secondary EFL classrooms. Foreign Language and Literature, 86(4), 242-248.

Swain, M. (2000). The output hypothesis and beyond: Mediating acquisition through collaborative dialogue. In J. P. Lantolf (Ed.), Sociocultural Theory 
and Second Language Learning (pp. 97-114). Oxford, UK: Oxford University Press.

Swain, M. (2005). The output hypothesis: Theory and research. In E. Heinkel (Ed.), Handbook of research in second language teaching and learning (pp. 471483). Mahwah, NJ: Lawrence Erlbaum Associates.

Van der Zwaard, R., \& Bannink, A. (2016). Nonoccurrence of negotiation for meaning in task-based synchronous computer-mediated communication. The Modern Language Journal, 100(3), 625-640. DOI: 10.1111/modl.12341

Varonis, E., \& Gass, S. (1985). Non-native/nonnative conversations: A model for the negotiation for meaning. Applied Linguistics, 6(1), 71-90. DOI: 10.1093/applin/6.1.71

Walsh, S. (2002). Construction or obstruction: Teacher talk and learner involvement in the EFL classroom.
Language Teaching Research, 6(1), 3-23. https://doi. org/10.1191/1362168802lr095oa

Walsh, S. (2006). Investigating classroom discourse. London, UK: Routledge.

Walsh, S. (2013). Classroom discourse and teacher development. Edinburgh, UK: Edinburgh University Press.

Yi, B., \& Sun, Z. (2013). An empirical study of the effectiveness of negotiation for meaning in L2 vocabulary acquisition of Chinese learners of English. English Language Teaching, 6(10), 120. http://dx.doi.org/10.5539/elt.v6n10p120

Yoshida, R. (2013). Conflict between learners' beliefs and actions: Speaking in the classroom. Language Awareness, 22(4), 371-388. http://dx.doi.org/10.108 $0 / 09658416.2012 .758129$ 